\section{Counseling Gifted Students: School-Based Considerations and Strategies}

Kelly Kennedy ${ }^{a,}{ }^{*}$, Jessica Farley ${ }^{a}$

\author{
Received: 16 September 2017 \\ Revised: 29 October 2017 \\ Accepted: 28 November 2017 \\ ISSN: 1307-9298 \\ Copyright (C) IEJEE \\ www.iejee.com
}

DOI: 10.26822/iejee.2018336194

\begin{abstract}
Gifted students are a heterogeneous group, inclusive of those of all cultures, backgrounds, interests, and achievements. Gifted students may not display any more or worse psychological, social, or developmental challenges than their peers, but they also are not immune from these challenges. Moreover, the nature of their giftedness may impact both how they experience a challenge and how a counselor might best support them. This article provides information regarding some developmental, emotional, and social challenges faced by gifted youth, as well as some suggestions for appropriate school-based counseling strategies.
\end{abstract}

Keywords: Counseling, gifted students, gifted and talented students.

\section{Introduction}

Counselors working in schools may primarily focus on students with below-average achievement, or who are atrisk for falling behind academically. Unfortunately, educators and counselors can overlook the developmental and emotional needs of gifted students, because these students are often meeting or exceeding educational expectations (Fisher \& Kennedy, 2016). In this article, we will provide an overview of gifted youth, with a focus on the diversity that exists within this group. We will also review the potential risks and challenges faced by gifted students in schools, and the strategies that school-based counselors may consider when working with gifted students.

Giftedness is one of many aspects of diversity that a school team must consider when supporting any student. Other dimensions of diversity that impact a student's social, academic, and identity development include race, gender, socioeconomic status, and sexual orientation. As with each of these factors, a student's giftedness is a part of their identity, and a counselor should consider how a student's skills, talents, or abilities may be interacting with other factors in their life when evaluating problem situations or forming treatment plans (Cross \& Cross, 2015). With the potential impact and interaction effects of giftedness in mind, counselors can tailor their treatment approaches to best meet the needs of this population of students (Fisher \& Kennedy, 2016).

\section{What is giftedness?}

Across time and across the globe, there have been and continue to be many different definitions of giftedness and methods for identifying gifted individuals. Some refer to this population as gifted, others use gifted and talented, and still others may identify those with high ability (i.e., high IQ), high academic achievement, or who stand out for remarkable skills or accomplishments across other fields such as art or music. McClain and Pfeiffer (2012) provide a broad definition that covers these various aspects and attributes, describing this population as those who "exhibit outstanding intellectual ability, or promise, and are capable of extraordinary performance and accomplishment" (p. 59). Peterson (2015) describes gifted individuals as those with exceptionally high ability, "regardless of academic performance" (p. 153). Thus, Peterson is arguing that a framework for this definition should be inclusive of both those who have remarkable achievements, as well as those with the capacity to do so. Throughout this article, we will use the term gifted, but we will try to be as inclusive of the broadest possible group of gifted individuals in our coverage of relevant challenges and recommended strategies for supporting these students. Similarly, we encourage all counselors to broaden their view to include the possibility of giftedness as we describe it in any of the students that they work with.

Methods for the identification of gifted students vary widely across and within countries. For example, within the United States, there are no national criteria for giftedness, and students are identified as gifted in varying ways across the 50 States (Fisher \& Kennedy, 2016). In Lebanon, little research has been conducted on both the period of adolescence (Ayyash-Abdo, 2007) or on gifted children (Saroupbim, 2009). The country lacks a formal system of education for gifted students, as the emphasis in the national school curriculum remains on mainstream education (Saroupbim, 2009). Conversely, in Israel, The Israeli Ministry's Division for Gifted and Talented Education is responsible for coordinating provision for gifted and talented children in the Israeli educational system and

\footnotetext{
a, ${ }^{*}$ Corresponding author: Kelly Kennedy, Donna Ford Attallah College of Educational Studies, Chapman University. One University Drive, Orange, CA 92866, USA. E-Mail: kkennedy@chapman.edu

${ }^{a}$ Chapman University, USA. E-mail addresses: (K. Kennedy) kkennedy@chapman.edu; (J. Farley) farle115@mail.chapman.edu

(c) 2018 Published by T\& K Academic. This is an open access article under the CC BY- NC- ND license. (https://creativecommons.org/licenses/by/4.0/)
} 
offers a variety of special programs for gifted and talented children nationwide (Zeidner \& Shani-Zinovich, 2013). According to the current policy of the Israeli Ministry of Education, special educational programs are offered to individuals who are identified as scholastically gifted, based on overall scholastic achievements and cognitive ability tests performance. The nature of each program and the educational program are determined by the instructions issued by the division and by the policy and needs of the local authorities, as well as the program directors. Each program serves students from a specific magnet area in Israel (Peyser, 2005).

Historic and traditional methods of identification often rely on one method of measurement, often a cognitive assessment (i.e., IQ) and a cutoff score (e.g., upper 5th percentile, standard score of 120 or above)(McClain \& Pfeiffer, 2012). This method can be problematic for a number of reasons. First, cognitive assessments, like all psychological assessments, inherently contain error. Scores from group administered cognitive assessments contain even more error than individually administered assessments (Hogan, 2015), meaning that the use of a cutoff score could miss a number of examinees whose true scores were masked by testing error. Other identification methods include multiple layers of testing, such as a 2-step process that involves cutoff scores for both cognitive and achievement tests, as is used in Israel (Zeidner \& ShaniZinovich, 2013). For example, Peterson and Lorimer (2011) describe an identification process that includes an IQ score of 2 or more standard deviations above the mean, as well as "commensurate" achievement as measured by test scores and grades (p. 169). Although these methods are more likely to capture more gifted students, reliance on standardized achievement scores will mean that students whose capacity is not yet realized will be missed, and will also exclude students with skills such as music, art, leadership, etc. Score-based methods are also likely to under-identify students with different cultural, economic, or circumstantial experiences (Peterson, 2015.

One of the greatest challenges in studying or working with gifted youth is the heterogeneity that exists within this group (Peterson, 2015; Reis \& Renzulli, 2009). Given the breadth of the definitions that exist, as well as the concept that this group includes both those who have exhibited extraordinary achievements and those who have the capacity to do so, along with variability inherent in the fact that gifted individuals also vary on all other dimensions of diversity, it is almost overwhelming to try to provide broad guidance regarding the needs and challenges of gifted youth. In this article, while we are providing suggestions and commonly cited or researched phenomena, we also recognize that with a group this diverse, we are at best providing broad guidance to school-based counselors wishing to work with gifted students. We urge all professionals to carefully consider the unique complexities that make up every child they work with, and hope that the following information provides some useful considerations as they determine their needs and provide supports.

Risks and Challenges of Gifted Youth

A counselor's understanding of the unique challenges that gifted students are more likely to face than their peers must be taken into context with all else that is know about each child as an individual. Family history, educational and life experiences, social history, and cultural, racial, or ethnic background may each also play roles in the current challenges faced by any given client that is referred for counseling. To effectively serve this population, a counselor must be careful to not assume that challenges are due just from a student's status as gifted (Levy \& Plucker, 2008), just as they should not assume that challenges are due just to any other factor of the student's identity. Rather, the student's unique development as a gifted person should be considered alongside what counselors know about other aspects of the student's identity, and counseling approaches may need to be tailored accordingly (Fisher \& Kennedy, 2016).

By definition, giftedness is an asset, not a risk factor. However, gifted students face the same circumstantial, life, family, and social issues as all students (Bakar \& Ishak, 2014; Zeidner \& Shani-Zinovich, 2013). Like all students, they may experience pain, loss, anxiety, and depression. When considering risks and challenges that gifted youth might face, counselors should keep two factors in mind. First, counselors must be cognizant that the social, emotional, or developmental needs of gifted students may be overlooked by others, especially if that student is performing well academically (Aljughaiman \& Tan, 2008). Second, a student's giftedness may interact with other risk factors and impact how students experience events or challenges (Cross \& Cross, 2015). Giftedness in and of itself does not cause problems or distress in students, but understanding a student's giftedness can help a counselor to best understand that student's challenges and how to support them in overcoming them.

Risks and challenges found in gifted students include stress, anxiety, social difficulties, social isolation, and depression (Bakar \& Ishak, 2014; Cross \& Cross, 2015; Fisher \& Kennedy, 2016; Levy \& Plucker, 2008). Gifted students are also at risk for underachievement, which is hypothesized to be due to social or emotional factors, or a lack of challenge, support, motivation, or engagement (Reis \& Renzulli, 2009). Further, there are several areas in which gifted students, in large part due to the very nature of their giftedness, may need great support for their social and emotional development. These include: perfectionism, academic anxiety, and asynchronous development (Fisher \& Kennedy, 2016)

\section{Counseling Recommendations for Gifted Students}

In general, counseling approaches for working gifted youth are not qualitatively different than strategies used for all students. However, small adjustments may need to be made as students' needs and development are accounted for (Cross \& Cross, 2015; Fisher \& Kennedy, 2016), both when evaluating needs and determining areas for support, as well as in how counseling techniques are implemented. In other words, all qualified counselors already possess the core knowledge needed to work effectively with this population, but they might need to adjust their perspective and approach slightly to be most effective with gifted students. 
Levy and Plucker (2008) recommend that competent counselors of gifted and talented client possess skills in three practical areas: 1) counseling and therapy skills; 2) consultation skills, and 3) advocacy skills. Other experts add that counselors working with gifted students should be able to teach stress management techniques and help to build social support networks (Reis \& Renzulli, 2004; Rice, Leever, Christpoher, \& Porter, 2006). Other resources that might be helpful with this population include mindfulness, meditation, deep breathing, progressive muscle relaxation, and guided imagery (Fisher \& Kennedy, 2016).

As foundational approaches to all school-based counseling, we recommend that practitioners are familiar with Cognitive-behavioral therapy (CBT) and Solutionfocused brief therapy (SFBT). Cognitive-behavioral therapy (CBT) is an evidence-based counseling approach built on the principle that feelings and behaviors are determined primarily by one's thoughts; they are cognitively mediated (Ronen, 2006). For further information on CBT, we recommend Cognitive therapy for adolescents in school settings (Creed, Reisweber, \& Beck, 2011), Child and adolescent therapy: Cognitive-behavioral procedures (Kendall, 2011), and Helping students overcome depression and anxiety: A practical guide (Merrell, 2008). Solutionfocused brief therapy (SFBT) is a strength-based counseling approach that focuses on solutions as a way of reconceptualizing and solving student's problems (Sklare, 2014). Solution-focused counseling works to expand the way a student thinks about problems and solutions by exploring any hints of variation and flexibility in the language of the student (Creed, Reisweber, \& Beck, 2011). For further information on SFBT, we recommend Solutionfocused brief therapy: A handbook of evidence-based practice (Franklin, Trepper, Gingerich, \& McCollum, 2012), Brief counseling that works: A solution-focused therapy approach for school counselors and other mental health professionals (Sklare, 2014), Solution-Focused counseling in schools (Murphy, 2015) and The power of groups: Solution-focused group counseling in schools (Cooley, 2009).

\section{Perfectionism and Academic Anxiety}

Given that giftedness is often identified via exceptional achievement or ability, it is not uncommon for gifted students to spend proportionately more time and energy in their area of ability that their same-aged peers (Greenspon, 2014; Levy \& Plucker, 2008). This intensity can manifest as perfectionism, or the need to strive toward perfection. Perfectionism is not unique to gifted individuals (Cross \& Cross, 2015), but perfectionism has been a focus of research in gifted learners (Wang, Fu, \& Rice, 2012). Perfectionism can be healthy or dysfunctional (Levy \& Plucker, 2008; Reis \& Renzulli, 2004; Rice, Leever, Christpoher, \& Porter, 2006; Wang, Fu, \& Rice, 2012), although the majority of the literature exploring perfectionism and gifted students focuses on dysfunctional perfectionism. Greenspon (2014) describes dysfunctional perfectionism as being characterized by intense anxiety, and as, "simultaneously a desire to be perfect and a fear of imperfection." (p. 988). There is a fine line between striving to reach high standards of excellence and feeling self-defeated through the inability to reach unrealistic expectations of perfection. When that line is crossed, the perfectionistic tendencies become disabling. In schools, perfectionism can lead to anxiety and underachievement (Cross \& Cross, 2015; Greenspon, 2014; Pyryt, 2004).

Some scholars have cautioned that the focus on dysfunctional perfectionism within gifted populations may not be a global phenomenon. For example, Fong and Yuen (2014) found that within populations of gifted Chinese students, positive perfectionism was more likely than negative perfectionism. These authors speculated that the traits of perfectionism may be more adaptive in Chinese than Western cultures, and that perhaps the high expectations that are sometimes placed upon gifted students are perceived more positively by Chinese students than their Western peers. Fong and Yuen suggest that when perfectionism is the target of a counseling intervention, counselors should aim to help students minimize or cope with negative aspects but that the overall goal should not be to eliminate perfectionism altogether. Given the variety of findings regarding perfectionism's potential impact, pervasiveness within the population of gifted students, and potential cultural differences in presentation, counselors should be particularly cautious in interpreting perceived perfectionism.

There are two major concerns about perfectionism for gifted students: underachievement and emotional turmoil (Delisle \& Galbraith, 2002). Although underachievement may seem asynchronous with the concept of giftedness, perfectionism can explain some underachievement in this population. Perfectionistic tendencies may lead gifted students to not submit work unless it is perfect, which may mean late work or work that is never submitted because it never meets the students' own expectations. As a result, they may receive poor or failing marks. In regard to emotional stress, perfectionism may cause feelings of worthlessness and depression when gifted individuals fail to live up to the unrealistic expectations they set for themselves (Pyryt, 2004). This has several implications for school-based mental health providers, namely the ability to identify perfectionism in gifted students as well as establish effective coping mechanisms/interventions for these students.

Counseling Strategies for Perfectionism. When framing interventions for perfectionism that is having a negative impact on students, it can be helpful to apply strategies, frameworks, and interventions that have been developed for anxiety. As with any intervention within a diverse population, no two gifted students' perfectionism or academic anxiety is going to manifest the same or be driven by the same thoughts, so interventions must always begin with taking the time to really get to know the student as an individual.

One way of looking at perfectionism from a CBT perspective is to break it down into the fundamental thoughts that perpetuate perfectionistic behaviors. Perfectionism can be viewed as a way of thinking or a way of thinking about one's self as they relate to the larger work. This is often attributed to a fear of failure, wherein a student comes to believe that if non-perfect performance is a failure, and that this failure is significantly 
representative of who they are and how they are valued, both by themselves and by others (Greenspon, 2014). Mistakes are a natural and often beneficial part of the learning process, but from this perspective, perfectionistic students may have extremely negative or maladaptive reactions because they view failures as directly reflective of their value as a person (Greenspon, 2014). One aspect of perfectionistic thinking is dichotomous (all-or-none) thinking, wherein the student believes that a grade is either perfect or it is worthless. An additional component of perfectionistic thinking is transforming desires (Wants) into demands (Musts). For example, a student who wants to do well on a test believes he or she must obtain a perfect score; otherwise they will view themselves as a failure. A third element of perfectionistic thinking is focusing on unmet goals and challenges rather than savoring successes. A student who gets a score of nine out of ten on an assignment dwells on the one missed point, rather than focusing on the overall high grade they received (Parker, 2000).

Considering the profound impact these thoughts have on how a student feels and behaves, the cognitive model works with the student to bring these thoughts to the surface and actively evaluate them (Creed, Reisweber, \& Beck, 2011). Thoughts that are helpful to the student are strengthened, whereas thoughts that are distorted or unhelpful are modified. The ongoing cycle depicting the ways in which feelings, thoughts, and behavior in a situation are related to each other can be exemplified by the example of a student who struggles with perfectionism. a B on an exam (triggering event), which leads the student to think, "I am a failure" (thought), feeling ashamed and anxious (feeling), and experiencing a panic attack (physical response). In this case, CBT aims to intervene in order to alter this cycle and create a more desirable outcome. It might begin by teaching the student relaxation techniques to manage the physical response; teaching the student how to identify his or her unhelpful automatic thoughts and counteract them with more helpful ones; and helping the student see himself or herself through a less critical lens (Fisher \& Kennedy, 2016). CBT can help to reframe the dichotomous (all-or-none) thinking that is typically characteristic of students struggling with perfectionism into a more accurate and healthy thought pattern (Pyryt, 2004).

A Solution-focused (SFBT) approach can also be helpful in addressing perfectionism. If a student's belief is that "If I do not receive an A it is the end of the world," SFBT can invite the student to consider broader ways of thinking about problems and solutions by encouraging them to focus on their strengths. For example, if the student received a 9 out of 10 on one test, they are encouraged to focus on the 9 questions they got right rather than the one they got wrong. Further, similar to CBT, solution-focused counseling can reduce dichotomous (all-or-none) thinking by cultivating a more realistic thought pattern. Considering many students with perfectionism tend to place their worth on their performance, solution-focused counseling aims to expand the student's self identity by separating the student from their problem (Murphy, 2015).
Other counseling strategies for coming with the anxiety associated with perfectionism include relaxation strategies, skill building, and guiding students through real or imaginary failures in a safe way (Cross \& Cross, 2015; Goetz, Preckel, Zeidner, \& Schleyer, 2008). Skill building can include teaching study or test-taking skills (Goetz et al., 2008). Counselors and other professionals working with gifted youth in educational settings accidently overlook the need for these skills in gifted youth when a student has displayed a pattern of high achievement. However, as students progress in school and are increasingly challenged, it may be that a gifted student who is not used to experiencing failure or frustration in learning is finally facing a skill, subject, or lesson that for the first time might require the study or test-taking skills that most students have either naturally developed or been taught over the course of their educational careers (Bakar \& Ishak, 2014; Reis \& Renzulli, 2009). Students can be taught to simultaneously work on these strategies as well as an overall self-awareness of when periods of stress are likely to be more intense for them (e.g., when exams are scheduled) (Rice, Leever, Christpoher, \& Porter, 2006).

\section{Other Academic Anxiety}

Outside of and in addition to perfectionism, gifted students may become anxious when faced with academic tasks such as test taking, to the point at which the anxiety becomes so overwhelming that it significantly interferes with their performance. Being barraged with anxious thoughts while trying to complete academic tasks is a negative form of multi-tasking and taxes working memory (Beilock \& Willingham, 2014). Anxious thoughts divert attention and thus degrade student performance, which can be especially prevalent in gifted students who exhibit perfectionistic thinking (Cassady \& Johnson, 2002). Recent research has examined the effectiveness of expressive writing in reducing anxiety among students.

Academic and performance-based anxiety in gifted students may be impacted by academic settings. When gifted students are in programs with only other gifted students, comparisons with their peers may shift, such that the student is no longer the highest achiever in his or her class. In gifted-centered classes or programs, gifted students may even have a heightened awareness of the achievement of their peers and how it compares with their own (Wang, Fu, \& Rice, 2012), and these students tend to exhibit higher levels of anxiety reasons for anxieity in this population: competition with other gifted students, real or perceived pressures for success or achievement placed upon them by others (Aljughaiman \& Tan, 2008; Goetz et. al., 2008; Zeidner \& Schleyer, 1999).

Counseling Strategies for Other Academic Anxiety. Recent research has examined the effectiveness of expressive writing (e.g., providing students with a few minutes to write about their feelings or about how they feel about their performance prior to a particular academic task, such as a test) in reducing academic anxiety among students. Park et al. (2014) propose that expressive writing helps to improve the performance of anxious students because it lessens the likelihood that math-related worries will capture attention during the task. Other authors suggest that writing about performance worries may free up working 
memory resources to help students better identify, differentiate, and understand their emotional experience (Gohm \& Clore, 2000), which can lead to the use of more effective emotion-regulation strategies during the test (Schmeichel \& Demaree, 2010).

Other counseling techniques designed for anxiety may also be effective in supporting gifted students through academic anxiety. Techniques focused on relaxation, such as meditation or progressive muscle relaxation strategies may be helpful (Fisher \& Kennedy, 2016), especially when students are taught these skills and how to self-implement relaxation when they are anxious (e.g., before or during an exam). When working with gifted youth regarding relaxation strategies, it may be beneficial to engage students on a cognitive level. For example, counselors could work with students to research the efficacy of these strategies, or encourage students to teach these strategies to others as a way to learn them better themselves (Kennedy \& Fisher, 2016). From a CBT perspective (e.g., Creed, Reisweber, \& Beck, 2011), counselors may work with students to identify and challenge negative or all-ornothing thoughts regarding exams and their performance that fuel anxiety. For example, a student may have thoughts such as, "If I don't score in the top of the class it means I am not smart," or "my classmates are smarter than me, therefore there is no way that I can perform well on this test." A counselor could help a student to identify and challenge the evidence for and accuracy of these statements, as well as to develop more positive self-talk.

\section{Asynchronous Development}

One of the challenges that gifted youth may face involves asynchronous development, which describes the concept that gifted youth are likely to be developmentally advanced in some areas, but not all (Cross \& Cross, 2015; Reis \& Renzulli, 2004; Zeidner \& Schleyer, 1999; Zeidner \& ShaniZinovich, 2013). For example, a gifted student may have extremely advanced skills in one area, such as verbal abilities, but have typically developing skills in areas such as social and emotional development. This can cause stress, anxiety, and social challenges.

Zeidner and Schleyer (1999) describe how asynchronous development may result in school-based test or performance anxiety in gifted students, as they may be more anxious over academic situations because they more deeply understand the implications of their performance than their peers. Cross and Cross (2015) describe how a gifted student may have fears or anxiety regarding facts or issues that his or her peers are unaware, such as when a gifted student's interest and ability leads her to read books that are designed for students who are older and more emotionally mature that she is. For example, a 7 year-old student may have the language skills to read novels typically assigned to secondary students, but that doesn't mean that this student would be emotionally ready to cope with the content of Dostoevsky's Crime and Punishment. Alternately, although many young children are interested in learning about dinosaurs, a gifted young child may ready about their deaths and be emotionally devastated by the permanence of those losses and the possibility that such a global catastrophe could happen to them. In many ways, the adults involved in a gifted student's personal and educational lives must be aware that even when a student is capable of reading or accessing certain advanced information, they may still have age-appropriate abilities to cope with the emotions or fears that may arise from that knowledge (Reis \& Renzulli, 2004).

Other authors have noted that asynchronous development may have an impact on a gifted student's social development and social relationships (e.g., Bakar \& Ishak, 2014; Cross \& Cross, 2015; Reis \& Renzulli, 2004). For example, some gifted students may have interests, fears, or other emotions that are more in line with older rather than their same-aged peers, and these difference may place a strain on relationships with classmates. Gifted students may be more socially mature than their peers, which might similarly inhibit social relationships or lead students to deny or hide giftedness or achievement levels for social reasons (Reis \& Renzulli, 2004). Children and adolescents don't always enjoy being different; students may feel isolated or be teased, bullied, or ashamed for a near endless list of ways in which they can stand out as being different (e.g., being exceptionally tall, having a physical disability, having an incarcerated parent, being from a minority culture or religion, etc.). Giftedness is no exception to this list, and some gifted students may seek to avoid, hide, or minimize their abilities in order to be more like their peers (Cross \& Cross, 2015).

Counseling Strategies and Supports for Asynchronous Development. Depending upon how asynchronous development may be impacting a student, a counselor has a variety of ways to provide support. If a child is experiencing anxiety due to learning or understanding a concept that is above their emotional maturity level, using psychoeducation to teach coping strategies may be beneficial. Self talk and other calming strategies would also be useful (Kennedy \& Fisher, 2016). Educating the adults in a gifted student's life can also help them to understand the concepts of asynchronous development, and to be cognizant that just because a student has the ability to cognitively grasp certain information, they may not have the emotional capacity to cope with it without support.

Group counseling interventions, tailored to the needs of gifted youth, can help students cope with social challenges associated with giftedness and/or asynchronous development, and there are many available social skills and friendship skills curricula that may be appropriate for use with gifted students in individual or group settings (Fisher \& Kennedy, 2016; Reis \& Renzulli, 2004). Counseling groups that include other gifted students can be a unique experience for gifted students who are used to being different from their classmates when it comes to abilities, accomplishments, or interests (Peterson, 2014). Such interventions could help students to build social networks by introducing other students with similar abilities or differences.

When selecting and utilizing programs for any counseling group, the relevance of the content and activities needs to be carefully reviewed and if necessary tailored to the needs of the students involved, and this step is especially important when considering group interventions for gifted students (Fisher \& Kennedy, 2016). Peterson and Lorimer 
(2011) describe a small group curriculum designed to meet the social and emotional needs of gifted students. Topics covered in this group intervention included personal and interpersonal skills (e.g., feelings, competitiveness, isolation, stress), academic and learning skills (e.g., time management, study skills, procrastination, perfectionism), and general skills (e.g., diversity, gender differences and stereotypes, career development). Reis and Renzulli (2004) suggest that counseling could be used to help students learn about other gifted individuals, thus helping students to better understand their own development as well as learn that there are others that have similar gifts and challenges. These authors suggest counseling activities such as reading biographies or watching films about gifted people may help inspire or encourage youth (Reis \& Renzulli, 2004), which can be done in individual or group settings.

Another method for supporting gifted students who may be experiencing social challenges due to asynchronous development is to guide students through a study of social development and social behaviors (Fisher \& Kennedy, 2015). In this approach, a counselor could function as a guide or coach, supporting students as they observe and report their findings regarding social phenomena, much as an anthropologist might do. For example, a student who is having trouble with peers because he or she has many interests that are not shared by his or her classmates may wish to learn more about the topics that his or peers find interesting or cool. The student and counselor could work together to discover what these might be, then the counselor could use further counseling sessions to help the student role play some age-appropriate conversation topics.

\section{Conclusion}

Gifted youth represent an exciting and challenging population for those providing mental health and other support services in school settings. The experiences, abilities, needs, and challenges of these students are as diverse as the students themselves. However, research on gifted students provides counselors with guidance regarding factors to consider and ideas regarding counseling strategies that may be effective in meeting the needs of these students. Above all, counselors should be cognizant that giftedness is one aspect of a student. It is not more or less important than all of the other factors that make that student who he or she is, but should always be taken into consideration when decisions are made on how to best support that student in times of need.

\section{References}

Aljughaiman, A., \& Tan, M. (2008). Anxiety in gifted female students in the Kingdom of Saudi Arabia. Gifted \& Talented International, 23(1), 49-54.

Ayyash-Abdo, H. (2007). Adolescence in Lebanon. In J.J. Amett (Ed.), International encyclopedia of adolescence, pp. 583-590. London: Routledge.

Bakar, A. Y. A. \& Ishak, N. M. (2014). Counseling services for Malaysian gifted students: An initial study. International Journal for the Advancement of Counseling, 36(4), 372383.
Beilock, S. \& Willingham, D. T. (2014). Math anxiety: Can teachers help students reduce it? American Educator, Summer, 43, 28-32.

Cassady, J. \& Johnson, R. (2002). Cognitive test anxiety and academic performance. Contemporary Educational Psychology, 27, 270-295.

Cooley, L. (2009). The power of groups: Solution-focused group counseling in schools. Thousand Oaks, CA: Sage.

Creed, T.A., Reisweber, J., \& Beck, A. T. (2011). Cognitive therapy for adolescents in school settings. New York: Guilford.

Cross, J. R. \& Cross, T. L. (2015). Clinical and mental health issues in counseling the gifted individual. Journal of Counseling \& Development 93, 163-172. doi:10.1002/j.1556-6676.2015.00192.x

Delisle, J. R., \& Galbraith, J. (2002). When gifted kids don't have all the answers: How to meet their social and emotional needs. Minneapolis, MN: Free Spirit.

Fisher, E. S., \& Kennedy, K. (2016). Counseling diverse populations in schools. New York: Oxford University Press.

Fond, R. W. \& Yuen, M. (2014). Perfectionism and Chinese gifted learners. Roeper Review, 36, 81-91. doi:10.1080/02783193,2014.884202

Franklin, C., Trepper, T. S., Gingerich, W. J., \& McCollum, E. E. (Eds.). (2012). Solution-focused brief therapy: $A$ handbook of evidence-based practice. New York: Oxford University Press.

Goetz, Preckel, Zeidner, M., \& Schleyer, E. (2008). Big fish in small ponds: A multilevel analysis of text anxiety and achievement in special gifted classes. Anxiety, Stress, \& Coping,21(2)185-198. doi:10.1080/10615800701628827

Gohm, C. L., \& Clore, G. L. (2000). Individual differences in emotional experience: Mapping scales to processes. Personality and Social Psychology Bulletin, 26, 679-697.

Greenspon, T. S. (2014). Is there an antidote to perfectionism? Psychology in the Schools, 51(9), 986-999. doi:10.1002/pits.21797

Hogan, T.P. (2015). Psychological testing: A practical introduction ( $3^{\text {rd }} E d$.). Hoboken, Jj: John Wiley \& Sons.

Kendall, P. C. (2011). Child and adolescent therapy: Cognitivebehavioral procedures ( $4^{\text {th }} \mathrm{ed}$.). New York: Guilford.

Lepore, S., Greenberg, M.A., Bruno, M., \& Smyth J. (2002). The writing cure: How expressive writing promotes health and emotional well-being. Washington: American Psychological Association.

Levy, J., \& Plucker, J. (2008). A multicultural competence model for counseling gifted and talented children. Journal of School Counseling, 6(4), 1-47. Retrieved from www.jsc.montana.edu/articles/v6n4.pdf

McClain, M., \& Pfeiffer, S. (2012). Identification of gifted students in the United States today: A look at state definitions, policies, and practices. Journal of Applied 
School Psychology, 28, 59-88.

doi:10.1080/15377903.2012.643757

Merrell, K. W. (2008). Helping students overcome depression and anxiety: A practical guide ( $2^{\text {nd }}$ ed.). New York: Guilford.

Murphy, J. (2015). Solution-Focused counseling in schools (3rd ed.). Virginia: American Counseling Association.

Parker, W D. (2000). Healthy perfectionism in the gifted. Journal for Secondary Gifted Education, 34, 173-182.

Peterson, J. S., \& Lorimer, M. (2011). Student response to a small-group affective curriculum in a school for gifted children. Gifted Child Quarterly, 55(3), 167-180. doi:10.1177/0016986211412770

Peyser, M. (2005). Identifying and nurturing gifted children in Israel. International Journal for the Advancement of Counselling, 27, 229-243.

Pyryt, M. (2004). Helping gifted students cope with perfectionism. National Association for Gifted Children.

Reis, S. M., \& Renzulli, J. S. (2009). Myth 1: The gifted and talented constitute one single homogenous group and giftedness is a way of being that stays in the person over time and experiences. Gifted Child Quarterly, 53(4), 233-235. doi:10.1177/0016986209346824

Reis, S. M., \& Renzulli, J. S. (2004). Current research on the social and emotional development of gifted and talented students: Good news and future possibilities. Psychology in the Schools, 41(1), 119-130. doi:10.1002/pit.10144

Rice, K. G., Leever, B. A., Christopher, J., \& Porter, J. D. (2006). Perfectionism, stress, and social (dis)connection: A short-term study of hopelessness, depression, and academic adjustment among honors students. Journal of Counseling Psychology, 53(4), 524534. doi:10.1037/0022-0167.53.4.524

Ronen, T. (2007). Cognitive behavior therapy with children and adolescents. In T. Ronen, A. Freeman, T. Ronen, A. Freeman (Eds.) Cognitive behavior therapy in clinical social work practice (pp. 189-211). New York, NY, US: Springer Publishing Co.

Sarouphim, K.M. (2009). The use of a performance assessment for identifying gifted Lebanese students: Is DISCOVER effective? Journal for the Education of the Gifted, 33, 275-295.

Schmeichel, B. J., \& Demaree, H. A. (2010). Working memory capacity and spontaneous emotion regulation: High capacity predicts self-enhancement in response to negative feedback. Emotion, 10(5), 739744. doi:10.1037/a0019355

Sklare, G. B. (2014). Brief counseling that works: A solutionfocused therapy approach for school counselors and other mental health professionals. Thousand Oaks: CA: Sage.

Wang, K. T., Fu, Chu-Chun, \& Rice, K. G. (2012). Perfectionism in gifted students: Moderating effects of goal orientation and contingent self-worth. School
Psychology Quarterly, 27(2), 96-108. doi:10.1037/a0029215

Zeidner, M. \& Schleyer, E. J. (1999). Test anxiety in intellectually gifted school students. Anxiety, Stress, and Coping, 12, 163-189.

Zeidner, M., \& Shani-Zinovich, I. (2013). Research on personality and affective dispositions in gifted children: The Israeli scene. Gifted and Talented International, 28(1), 35-50. 
This page is intentionally left blank

www.iejee.com 